\title{
Effect of thickness and matrix variability on properties of a starch-based nanocomposite supple film
}

\author{
${ }^{1, * \text { Fadeyibi, A. and }}{ }^{2}$ Osunde, Z.D. \\ ${ }^{1}$ Department of Food and Agricultural Engineering, Faculty of Engineering and Technology, Kwara State \\ University, Malete, Nigeria \\ ${ }^{2}$ Department of Agricultural and Bioresources Engineering, Federal University of Technology, Minna, \\ Nigeria
}

\begin{abstract}
Article history:
Received: 24 April 2021

Received in revised form: 27

May 2021

Accepted: 10 August 2021

Available Online: 31 August

2021

Keywords:

Film,

Nanocomposite,

Properties,

Starch,

Thickness

DOI:

https://doi.org/10.26656/fr.2017.5(4).281
\end{abstract}

\section{Introduction}

Postharvest activities are often associated with some losses in the agricultural value chain. These were estimated to vary between $5-25 \%$ in the industrialized nations and $20-50 \%$ in developing countries (Ehiem et al., 2009). Abimbola (2014) reported that over 50\% of harvested fruits and vegetables in Nigeria get spoilt annually, because of poor packaging, storage, and processing, leading to seasonal shortages and fluctuation in the supply and prices. Most of the materials used in packaging industries are produced from petroleum-based non-degradable monomers. Kirwan et al. (2011) reported a 37\% increase in the amount of non-degradable polymer wastes between 1998 and 2005. Consequently, by 2020 the amount is expected to double around 462 million tons. Siracusa et al. (2008) reported that synthetic packaging materials alone have accounted for almost two -thirds by volume of the total packaging wastes the world over. Therefore, there is a need for an alternative packaging material that can help address the problem (Sorrentino et al., 2007). The bio-based film is a good example of an alternative packaging approach. The material has been reportedly used for shelf-life extension of packaged food products (Tharanathan, 2003). Also, since the substrates constituting the material can be degraded on exposure to extreme heat, they could potentially solve the waste problem. The material properties of the biodegradable film can be improved by the addition of nanoparticles (Fadeyibi et al., 2017; Farbodi, 2017). This is made possible with the inclusion of the nanoparticles, with particle size approximately $<$ $100 \mathrm{~nm}$ and bonded with the adjacent phases of the starch molecules. Structurally, the characteristics of the packaging material may be largely responsible for its suitability for food applications (Giannelis et al., 1999).

Nanocomposite films have found numerous applications in the packaging of fruits and vegetables (Wu et al., 2005). For instance, the shelf-lives of okra, tomatoes and fresh orange juice have been improved with the nanocomposite film prepared from the blends of low-density polyethylene with silver and cassava starch with zinc nanoparticles (Fadeyibi, Osunde, Agidi, Idah et al., 2016; Fadeyibi et al., 2019). The shelf-life of freshly packaged oranges has been enhanced up to 28 days without any negative effect on its sensory quality with the addition of nano-zinc into the matrix of the packaging material (Emamifar et al., 2011). Motlagh et al. (2006) reported a decrease in the microbial, and mould growth and an increase in the organoleptic parameters of dried barberry in their work on the effects 
of polyethylene packages containing micrometre-sized silver particles on the quality and shelf life of the product. Additionally, the application of nanocomposite edible film, made from the blend of cellulose nanofibers with mango purees, has been used for fruits and vegetable packaging (Azeredo et al., 2009). However, the effects of the uniform dispersion of the constituent materials or matrix variability on the physical properties of the nanocomposite film have not been reported. Although Fadeyibi, Osunde, Agidi, Idah et al. (2016) developed and optimized nanocomposite film from the blend of zinc nanoparticle and glycerol, the authors did not report the effect of the matrix variability and thickness on the properties of the film. It is therefore necessary to investigate the effects of these parameters on the behaviour of the film to ascertain the right combination for a specific application. This research was carried out to determine the effect of the thickness, glycerol, and zinc-nanoparticles on the properties of the nanocomposite flexible film using the surface response methodology.

\section{Materials and methods}

\subsection{Preparation of nanocomposite film}

Starch was prepared by processing $2 \mathrm{~kg}$ of cassava roots using the procedure described by Fadeyibi et al. (2014). The nanocomposite was prepared by mixing the starch (1 kg), glycerol $(45-55 \% \mathrm{w} / \mathrm{v})$, and zincnanoparticles $(0-2 \% \mathrm{w} / \mathrm{v})$ to form a thermoplastic film with a thickness in the range of 15- $17 \mu \mathrm{m}$, as described by Emamifar et al. (2011), Motshekga et al. (2015), Fadeyibi, Osunde, Agidi, Idah et al. (2016) and Fadeyibi et al. (2017). A total of 27 film samples were produced and sealed in the polyethylene packs to avoid possible hydration.

\subsection{Determination of the properties of the film}

ASTM Standards procedure was used to determine the water vapour permeability (WVP) while the sorption method was used to determine the oxygen permeability (OP) of the nanocomposite films as described by Motshekga et al. (2015) and Fadeyibi, Osunde, Agidi, Idah et al. (2016). The nanoindenter machine (Nano Mechanical Test System-Hysitron TI750) was used to carry out the mechanical test on the samples of the cassava starch nanofilm at the Physics Laboratory of the Sheda Science and Technology Complex (SHESTCO), Abuja, Nigeria. A record of the depth and area of the indented surfaces were made during this process (Fadeyibi, Osunde, Agidi, Egwim et al., 2016). While indenting, the average values of the reduced modulus, hardness, strain energy, drift rate and tensile strength were measured and recorded.
The thermal properties of the cassava starch nanozinc oxide films were determined using the Thermogravimetric Analyzer, at the Centre of Genetic Engineering and Biotechnology of the Federal University of Technology Minna. The chillers are set at a temperature of $15^{\circ} \mathrm{C}$ to maintain the right cooling medium for the TGA equipment. The equipment is then switched on in a range of 30 to $950^{\circ} \mathrm{C}$ temperature scan while nitrogen gas was released from the cylinder for 30 mins at the pressure, flow, and heating rates 2.5 bar, 20 $\mathrm{mL} / \mathrm{min}$ and $10^{\circ} \mathrm{C} / \mathrm{min}$, respectively. The weight of the crucible was zeroed and a mass of $2 \mathrm{mg}$ of the sample was loaded in the TGA thermo-balance, with continuous weighing as heating progresses. Finally, the program was initiated and the weight (\%) and time (min) data were measured as the temperature approached $950^{\circ} \mathrm{C}$ from the room temperature. The procedure was replicated for all samples of the nanofilm.

\subsection{Determination of optimum parameters}

Response surface methodology (RSM) was applied to determine the optimum conditions of process variables for the characterized properties of the films, namely mechanical, barrier properties and thermal stability. Data from a previous report and preliminary trials were considered to select the number and range of process variables in the experimental design. The process variables considered were the thickness of the film (A; $15,16,17 \mu \mathrm{m})$, the concentration of glycerol (B; 45, 50, $55 \% \mathrm{w} / \mathrm{v}$ ) and the concentration of zinc nanoparticles (C; $0,1,2 \% \mathrm{w} / \mathrm{w})$, while the dependent response variable chosen were the characterized attributes of the films, as shown in Table 1.

Table 1. Properties of the variables showing allowable ranges and constraints

\begin{tabular}{cccccc}
\hline \multirow{2}{*}{ Variation } & \multirow{2}{*}{ Unit } & \multicolumn{4}{c}{ Allowable Range } \\
\cline { 3 - 5 } & & -1 & 0 & 1 & \\
\hline $\mathrm{A}$ & $\mu \mathrm{m}$ & 15 & 16 & 17 & $-1<\alpha \leq 1$ \\
$\mathrm{~B}$ & $\mathrm{w} / \mathrm{w}$ & 45 & 50 & 4 & $-1<\alpha \leq 1$ \\
$\mathrm{C}$ & $\mathrm{w} / \mathrm{w}$ & 0 & 1 & 2 & $-1<\alpha \leq 1$ \\
\hline
\end{tabular}

\subsection{Experimental design}

A Box-Behnken Design (BBD), which includes 17 experiments formed by 5 central points, was employed to minimize the cost of running a $3^{3}$ full factorial experiment. The layout of the combinations of the process variables and the characterized attributes of the cassava starch nanocomposite films in the BBD are shown in Table 2. The optimization was based on finding the desirability for the objective function (Vargas-Lopez et al., 1990). The objective functions, here are to maximise the reduced modulus, hardness, tensile strength, deformation while minimising the strain energy for mechanical properties. It was also designed to 
minimise both the OP and WVP for barrier properties while minimising the thermal stability and weight loss for thermal properties.

Table 2. Variable combination as used in BBD

\begin{tabular}{cccc}
\hline \multirow{2}{*}{$\mathrm{S} / \mathrm{n}$} & \multicolumn{3}{c}{ Variables } \\
\cline { 2 - 4 } & $\mathrm{A}$ & $\mathrm{B}$ & $\mathrm{C}$ \\
\hline 1 & 16 & 55 & 1 \\
2 & 15 & 55 & 1 \\
3 & 15 & 50 & 0 \\
4 & 15 & 50 & 2 \\
5 & 16 & 50 & 1 \\
6 & 17 & 45 & 1 \\
7 & 16 & 45 & 2 \\
8 & 15 & 45 & 1 \\
9 & 16 & 50 & 1 \\
10 & 16 & 45 & 0 \\
11 & 16 & 50 & 1 \\
12 & 16 & 50 & 1 \\
13 & 17 & 55 & 1 \\
14 & 17 & 50 & 0 \\
15 & 16 & 55 & 0 \\
16 & 16 & 55 & 2 \\
17 & 17 & 50 & 2 \\
\hline
\end{tabular}

\section{Results and discussion}

3.1 Effect of thickness and matrix variability on the barrier properties of the film

The variations of the effects of concentrations of glycerol and thickness of the films on the WVP and OP of the cassava starch nanocomposite films are shown in Figure 1 and Figure 2. In Figure 1, the $\mathrm{OP}$ increases from $4.81 \times 10^{-12}$ to $1.53 \times 10^{-11} \mathrm{~g} / \mathrm{m}$.Pa.s with an increase in the thickness of the films, a decrease in the concentration of glycerol and an increase in the interaction between the factors. In Figure 2, the WVP increases from $7.97 \times 10^{-11}$ to $3.64 \times 10^{-10} \mathrm{~g} / \mathrm{m}$.Pa.s with a decrease in the thickness of the films, an increase in the glycerol concentration and an increase in the interaction between the factors. The study of the barrier properties of biodegradable film is common in the food industry because it permits the understanding of the role of oxygen and water in deteriorative reactions. Water acts as a solvent or carrier and causes texture degradation, chemical and enzymatic reactions. Also, the water activity of foods is an important parameter in relation to the shelf-life of the food. In low-moisture foods, low levels of water activity must be maintained to minimize the deteriorative chemical and enzymatic reactions and to prevent texture degradation. When considering a suitable barrier in foods and food packaging the barrier properties of biopolymer films are important parameters (Aydinli et al., 2000; Kang et al., 2010; Kaur et al., 2017).

\subsection{Effect of thickness and matrix variability on the mechanical properties of the film}

\subsubsection{Reduced modulus of the film}

The variation of the reduced modulus of the cassava starch nanocomposite films with the concentration of glycerol, thickness of the films and their interaction is shown in Figure 3. The reduced modulus increases from 2.24 to $185.2 \mathrm{MPa}$ with an increase in the concentration of glycerol, a decrease in the thickness of the films and an increase in the interaction of both factors. The best prediction among all the treatment combinations of the films was $59.91 \%$ glycerol, $16.29 \mu \mathrm{m}$ and $1 \%$ of the zinc nanoparticles with a reduced modulus of $113.56 \mathrm{MPa}$. The reduced modulus can be regarded as a basic property of a material, which determines the deformation response to an applied load. In polymer nanocomposites, one of the most important theoretical efforts is to predict the reduced modulus. Therefore, the nearest film closer to the desired optimal reduce modulus, among the available treatments, was the one containing 55\% glycerol and $1 \%$ of the zinc nanoparticles with a thickness of $17 \mu \mathrm{m}$.

\subsubsection{Hardness of the film}

The variation of the hardness of the cassava starch nanocomposite films with the concentration of glycerol,

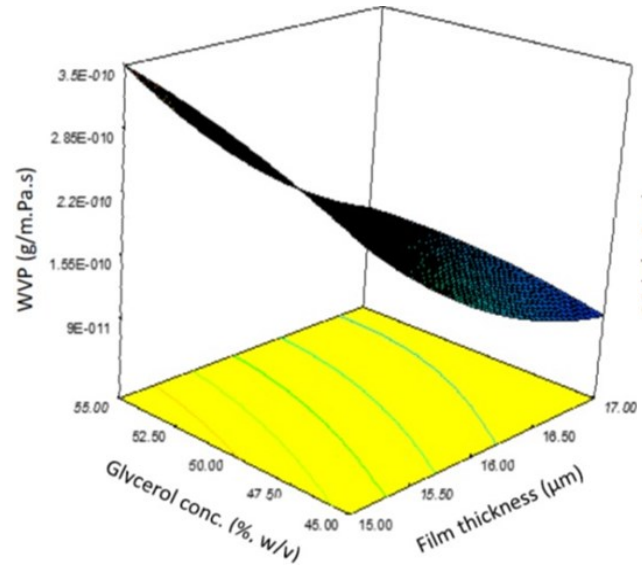

Figure 1. Effects of glycerol concentration and film thickness on water vapor permeability

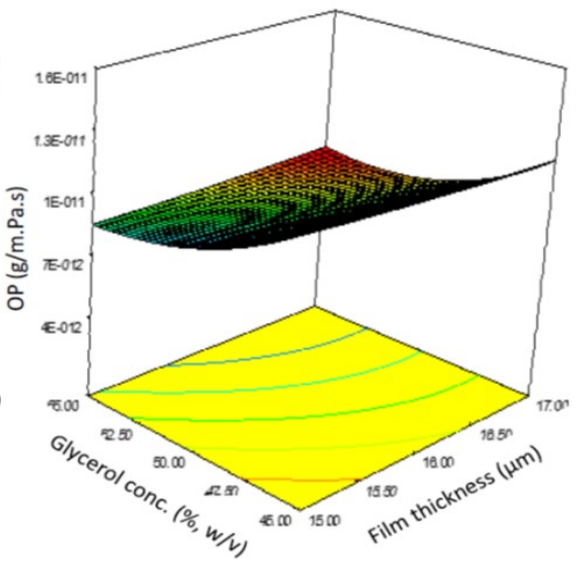

Figure 2. Effects of glycerol concentration and film thickness on oxygen permeability

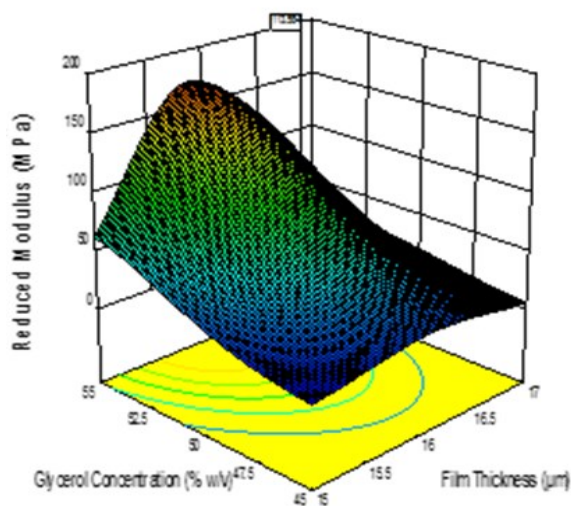

Figure 3. Effects of glycerol concentration and thickness on the reduced modulus of the film 
thickness of the films and their interaction is shown in Figure 4. The hardness increased from 1.01 to 765.56 $\mathrm{MPa}$ with an increase the thickness, irrespective of the concentration of the glycerol or the interaction between both factors. The best prediction among all the treatment combinations of the films was $55 \%$ glycerol, $16.27 \mu \mathrm{m}$ and $1.24 \%$ zinc nanoparticles with a hardness value of 15.88 MPa. The hardness of the film is an indication of its stability at the sub-atomic scale level, and this can enhance its application in food packaging. In particular, Gersappe (2002), who studied the effect of particle size on the mechanical properties of the biodegradable film, reported an increase in the toughness with particle size variability. Adnan et al. (2007) reported an enhanced toughness of amorphous polyethylene nanocomposites with the inclusion of fullerene buckyball fillers. In the presence of spherical nanoparticles, Sen et al. (2005) reported an increase in the elastic region during the deformation and the hardness of most plastic nanocomposites. Therefore, the nearest film closer to the desired optimal hardness, among the available treatments, was the one containing 55\% glycerol and $2 \%$ of the zinc nanoparticles with a thickness of $17 \mu \mathrm{m}$.

\subsubsection{Strain energy of the film}

The variation of the strain energy of the cassava starch nanocomposite films with the concentration of glycerol, thickness of the films and their interaction is shown in Figure 5. The strain energy increases from 14.54 to $11878 \mathrm{pNm}$ with an increase in the concentration of glycerol, a decrease in the thickness of the films and the interaction between both factors. The best prediction among all the treatments combinations of the films was $55 \%$ glycerol, $17 \mu \mathrm{m}$ and $1 \%$ of the zinc nanoparticles with strain energy of $158.433 \mathrm{pNm}$. Therefore, the nearest film closer to the desired optimal strain energy, among the available treatments, was the one containing $55 \%$ glycerol and $1 \%$ of the zinc nanoparticles with a thickness of $17 \mu \mathrm{m}$.

\subsubsection{Drift rate of the film}

The variation of the drift rate of the cassava starch nanocomposite films with the concentration of glycerol, thickness of the films and their interaction is shown in Figure 6. The drift rate increases from 7.48 to $25.55 \mathrm{~nm} / \mathrm{s}$ with an increase in thickness of the films but decreases with an increase in the concentration of the glycerol and interaction between the variables. The best prediction for the combination among all the treatments of the films was $49.13 \%$ glycerol, $16.93 \mu \mathrm{m}$ and $0.54 \%$ of the zinc nanoparticles with a reduced modulus of $25.35 \mathrm{~nm} / \mathrm{s}$. Drift rate can be described as the time-dependent creep behaviour, occurring due to the action of a static load on the nanocomposite film. The drifting may also take place under stress, provided the applied force is not sufficient to cause the material to yield. The results of many studies have shown that the addition of nanoparticles into biofilms may significantly improve the drift resistance of the biodegradable material (Pérez et al., 2008; Dasari et al., 2009). The findings of Yang et al. (2006), who investigated the tensile creep resistance of polyamide nanocomposites reinforced with clay nanoparticles, corroborates the findings of the present study. Also, the finding of Ohji (1996), who reported a delayed fracture behaviour under tensile loading at high temperatures for silicon nitride, silicon carbide, and alumina carbide nanocomposites, is in line with this research. The results showed that silicon carbide had an excellent creep resistance, even at very high temperatures, and the creeping effects were well described by a diffusive crack growth model. Moreover, the dispersion of silicon carbide nanoparticles into an alumina matrix led to a dramatic improvement in creep resistance when compared to alumina with equivalent grain size. This improvement was attributed to the impedance of grain boundary sliding, induced by the presence of intergranular silicon carbide nanoparticles. Therefore, the nearest film closer to the desired optimal drift rate, among the available treatments, was the one containing

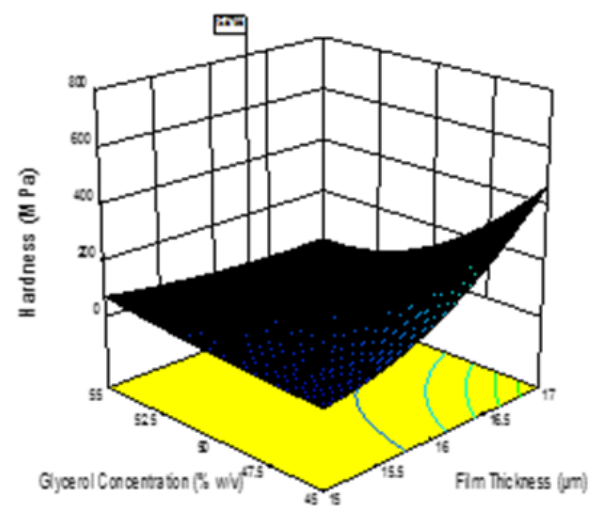

Figure 4. Effects of glycerol concentration and thickness on the hardness of the film

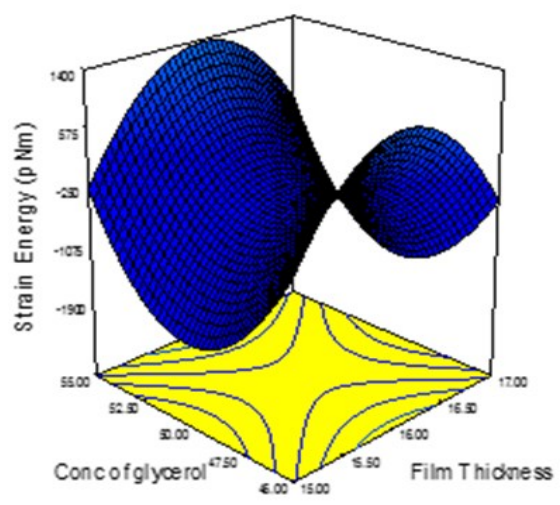

Figure 5. Effects of glycerol concentration and thickness on Strain Energy of the film

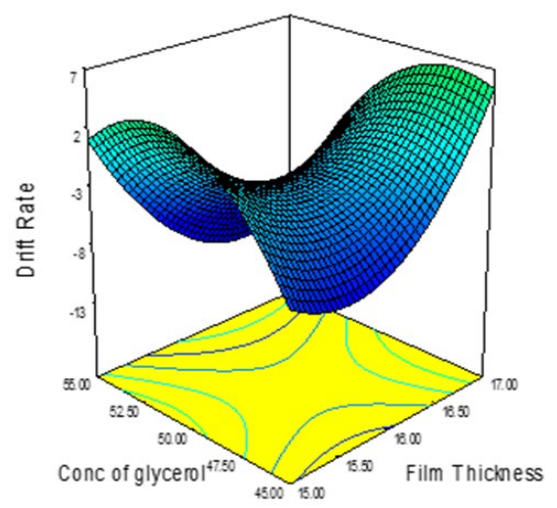

Figure 6. Effects of glycerol concentration and thickness on the drift rate of the film 
$50 \%$ glycerol and $1 \%$ of the zinc nanoparticles with a thickness of $17 \mu \mathrm{m}$.

\subsubsection{Tensile strength of the film}

The variation of the tensile strength of the cassava starch nanocomposite films with the concentration of glycerol, thickness of the films and their interaction is shown in Figure 7. The tensile strength increases from 0 to $0.4 \mu \mathrm{N} / \mathrm{nm}^{2}$ with an increase in the concentration of glycerol but decreases with an increase in the thickness of the films. The best prediction for the combination among all the treatments of the films was 55\% glycerol, $16.27 \mu \mathrm{m}$ and $1.27 \%$ zinc nanoparticles with a reduced modulus of $0.23 \mu \mathrm{N} / \mathrm{nm}^{2}$. Accurate quantification of the tensile strength of the individual component in the matrix of the film is essential for the understanding of the overall elastic performance of the nanocomposite material. In a related investigation, Suter et al. (2007) studied the tensile strength of the individual clay platelets in a composite matrix. Similarly, Capaldi et al. (2006) and Patel et al. (2018) reported that the average modulus and strength of a crystalline octacyclopentyl polyhedral film increase with an increase in the concentration of the nanoparticles. The above-predicted properties may be applicable to micromechanical models suitable for tensile strength prediction. Therefore, the nearest film closer to the desired optimal tensile strength, among the available treatments, was the one containing $55 \%$ glycerol and $2 \%$ of the zinc nanoparticles with a thickness of $17 \mu \mathrm{m}$.

\subsection{Effects of thickness and matrix variability on thermal properties of the film}

\subsubsection{Thermal stability of the film}

The variation of the thermal stability of the cassava starch nanocomposite films with the concentration of glycerol, thickness of the films and their interaction is shown in Figure 8 . The thermal stability increases from 59.70 to $60.43^{\circ} \mathrm{C}$ with a decrease in the concentration of glycerol and an increase in the thickness of the films.

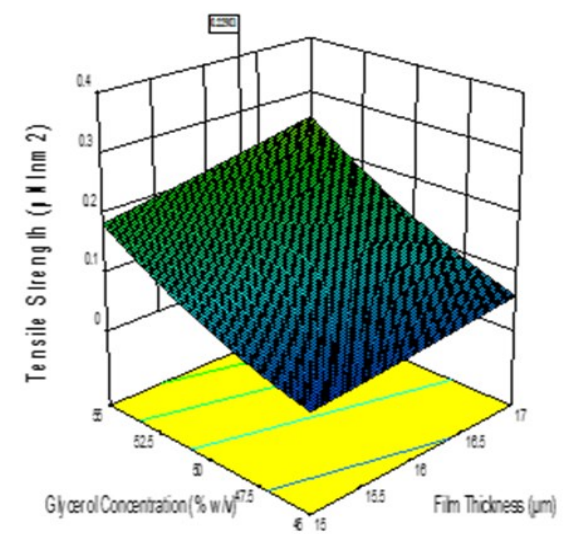

Figure 7. Effect of glycerol concentration and thickness on Tensile Strength of the film

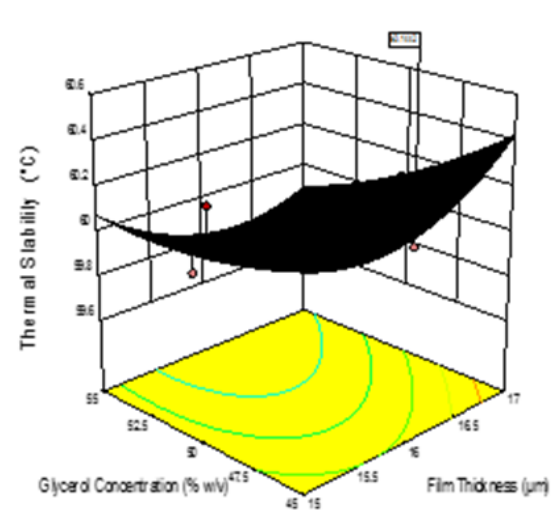

Figure 8. Effects of glycerol concentration and thickness on the thermal stability of the film

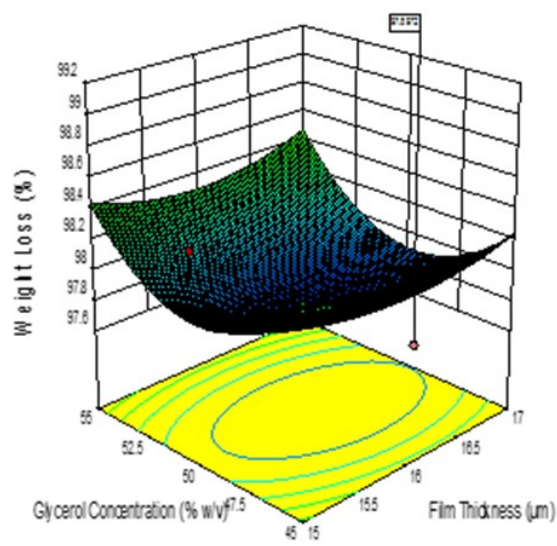

Figure 9. Effects of glycerol concentration and thickness on degradation weight loss of the film 
increased from 1.01 to $765.56 \mathrm{MPa}$ with an increase the thickness, irrespective of the concentration of the glycerol or the interaction between both factors. The strain energy increases from 14.54 to $11878 \mathrm{pNm}$ with an increase in the concentration of glycerol, a decrease in the thickness of the films and the interaction between both factors. The drift rate increases from 7.48 to 25.55 $\mathrm{nm} / \mathrm{s}$ with an increase in the thickness of the films. The thermal stability increases from 59.70 to $60.43^{\circ} \mathrm{C}$ with a decrease in the concentration of glycerol and an increase in the film thickness. The optimal film contains $55 \%$ glycerol, $2 \%$ zinc nanoparticles with a thickness of 17 $\mu \mathrm{m}$ with a desirability index of 0.95 .

\section{Conflict of interest}

The authors declare no conflict of interest.

\section{Acknowledgements}

The authors appreciate the financial support provided by the Tertiary Education Trust Fund via Institutional Based Research Intervention.

\section{References}

Adnan, A., Sun, C.T. and Mahfuz, H. (2007). A molecular dynamics simulation study to investigate the effect of filler size on elastic properties of polymer nanocomposites. Composites Science and Technology, 67(3-4), 348-356. https:// doi.org/10.5897/JSPPR2014.0160

Aydinli, M. and Tutas, M. (2000). Water sorption and water vapour permeability properties of polysaccharide (locust bean gum) based edible films. LWT-Food Science and Technology, 33(1), 63 $-67$. j.compscitech.2006.09.015

Azeredo, H.M., Mattoso, L.H.C., Wood, D., Williams, T.G., Avena-Bustillos, R.J. and McHugh, T.H. (2009). Nanocomposite edible films from mango puree reinforced with cellulose nanofibers. Journal of Food Science, 74(5), N31-N35. https:// doi.org/10.1111/j.1750-3841.2009.01186.x

Capaldi, F.M., Boyce, M.C. and Rutledge, G.C. (2006). The mechanical properties of crystalline cyclopentyl polyhedral oligomeric silsesquioxane. The Journal of Chemical Physics, 124(21), 214709. https:// doi.org/10.1021/jp045388p

Dasari, A., Yu, Z.Z. and Mai, Y.W. (2009). Fundamental aspects and recent progress on wear/scratch damage in polymer nanocomposites. Materials Science and Engineering: R: Reports, 63(2), 31-80. https:// doi.org/10.1016/j.mser.2008.10.001
Ehiem, J.C., Irtwange, S.V. and Obetta, S.E. (2009). Design and development of an industrial fruit and vegetable dryer. Research Journal of Applied Sciences, Engineering and Technology, 1(2), 44-53. https://doi.org/10.1088/1757-899X/197/1/012037

Emamifar, A., Kadivar, M., Shahedi, M. and Soleimanian-Zad, S. (2011). Effect of nanocomposite packaging containing $\mathrm{Ag}$ and $\mathrm{ZnO}$ on inactivation of Lactobacillus plantarum in orange juice. Food Control, 22(3-4), 408-413. https:// doi.org/10.1088/1757-899X/197/1/012037

Fadeyibi, A., Osunde, Z.D. and Yisa, M.G. (2019). Prediction of Some Physical Attributes of Cassava Starch-Zinc Nanocomposite Film for FoodPackaging Applications. Journal of Packaging Technology and Research, 3(1), 35-41. https:// doi.org/10.1007/s41783-018-0046-1

Fadeyibi, A., Osunde, Z.D., Agidi, G. and Evans, E.C. (2014). Flow and strength properties of cassava and yam starch-glycerol composites essential in the design of handling equipment for granular solids. Journal of Food Engineering, 129, 38-46. https://doi.org/10.1016/j.jfoodeng.2014.01.006

Fadeyibi, A., Osunde, Z.D., Agidi, G., Idah, P.A. and Egwim, E.C. (2016). Development and optimisation of cassava starch-zinc-nanocomposite film for potential application in food packaging. Journal of Food Processing and Technology, 7(6), 1000591. https://doi.org/10.4172/2157-7110.1000591.

Fadeyibi, A., Osunde, Z.D., Agidi, G., Egwim, E.C. and Idah, P.A. (2016). Nano-rheological behaviour of cassava starch-zinc-nanocomposite film under dynamic loading for high speed transportation of packaged food. In Poletto, M. (Ed.) Composite from renewable and sustainable materials, p. 241-254. InTech E-Book. https://doi.org/10.5772/64984.

Fadeyibi, A., Osunde, Z.D., Egwim, E.C. and Idah, P.A. (2017). Performance evaluation of cassava starchzinc nanocomposite film for tomatoes packaging. Journal of Agricultural Engineering, 48 (3), 137-146. https://doi.org/10.4081/jae.2017.565

Farbodi, M. (2017). Application of taguchi method for optimizing of mechanical properties of polystyrenecarbon nanotube nanocomposite. Polymers and Polymer Composites, 25(2), 177-184. https:// doi.org/10.1177/096739111702500208

Gersappe, D. (2002). Molecular mechanisms of failure in polymer nanocomposites. Physical Review Letters, 89(5), 058301. https://doi.org/10.1103/ PhysRevLett.89.058301

Giannelis, E.P., Krishnamoorti, R. and Manias, E. (1999). Polymer-silicate nanocomposites: model 
systems for confined polymers and polymer brushes. In Polymers in confined environments, p. 107-147. Berlin, Heidelberg, Germany: Springer. https:// doi.org/10.1007/3-540-69711-X_3

Kang, H.J. and Min, S.C. (2010). Potato peel-based biopolymer film development using high-pressure homogenization, irradiation, and ultrasound. $L W T$ Food Science and Technology, 43(6), 903-909. https://doi.org/10.1016/j.lwt.2010.01.025

Kaur, A., Kumar, A., Singh, P. and Kundu, K. (2017). Production, Analysis and Optimization of Low Cost Briquettes from Biomass Residues. Advances in Research, 12(4), 1-10. https://doi.org/10.9734/ AIR/2017/37630

Kirwan, M.J., Plant, S. and Strawbridge, J.W. (2011). Plastics in food packaging. In Coles, R. and Kirwan, M. (Eds.) Food and Beverage Packaging Technology. $2^{\text {nd }}$ ed., p. 157-212. United Kingdom: Blackwell Publishing Ltd. https:// doi.org/10.1002/9781444392180.ch7

Motlagh, S., Ravines, P., Karamallah, K.A. and Ma, Q. (2006). The analysis of Acacia gums using electrophoresis. Food Hydrocolloids, 20(6), 848854. https://doi.org/10.1016/j.foodhyd.2005.08.007

Motshekga, S.C., Ray, S.S., Onyango, M.S. and Momba, M.N. (2015). Preparation and antibacterial activity of chitosan-based nanocomposites containing bentonite -supported silver and zinc oxide nanoparticles for water disinfection. Applied Clay Science, 114, 330339. https://doi.org/10.1016/j.clay.2015.06.010

Ohji, T., Hirano, T., Nakahira, A. and Niihara, K. (1996). Particle/matrix interface and its role in creep inhibition in alumina/silicon carbide nanocomposites. Journal of the American Ceramic Society, 79(1), 33-45. https://doi.org/10.1111/j.11512916.1996.tb07877.x

Patel, H., Rajai, V., Das, P., Charola, S., Mudgal, A. and Maiti, S. (2018). Study of Jatropha curcas shell biooil-diesel blend in VCR CI engine using RSM. Renewable Energy, 122, 310-322. https:// doi.org/10.1016/j.renene.2018.01.071

Pérez, C.J., Alvarez, V.A. and Vazquez, A. (2008). Creep behaviour of layered silicate/starchpolycaprolactone blends nanocomposites. Materials Science and Engineering: A, 480(1-2), 259-265. https://doi.org/10.1002/smll.200400027

Sen, T.Z., Sharaf, M.A., Mark, J.E. and Kloczkowski, A. (2005). Modeling the elastomeric properties of stereoregular polypropylenes in nanocomposites with spherical fillers. Polymer, 46(18), 7301-7308. https://doi.org/10.1016/j.polymer.2005.05.098

Siracusa, V., Rocculi, P., Romani, S. and Dalla Rosa, M.
(2008). Biodegradable polymers for food packaging: a review. Trends in Food Science and Technology, 19(12), 634-643. https:// doi.org/10.1016/j.tifs.2008.07.003.

Sorrentino, A., Gorrasi, G. and Vittoria, V. (2007). Potential perspectives of bio-nanocomposites for food packaging applications. Trends in Food Science and Technology, 18(2), 84-95. https:// doi.org/10.1016/j.tifs.2006.09.004

Suter, J.L., Coveney, P.V., Greenwell, H.C. and Thyveetil, M.A. (2007). Large-scale molecular dynamics study of montmorillonite clay: the emergence of undulatory fluctuations and determination of material properties. The Journal of Physical Chemistry C, 111(23), 8248-8259. https:// doi.org/10.1021/jp070294b

Tharanathan, R.N. (2003). Biodegradable films and composite coatings: past, present and future. Trends in food science and technology, 14(3), 71-78. https:// doi.org/10.1016/S0924-2244(02)00280-7

Vargas-Lopez, J.M., Paredes-Lopez, O. and Espitia, E. (1990). Evaluation of lime heat treatment on some physicochemical properties of amaranth flour by response surface methodology. Cereal Chemistry, 67 (5), 417-421.

Wu, Z.B., Diestler, D.J. and Zeng, X.C. (2005). Multiscale treatment of thin-film lubrication. Molecular Simulation, 31(12), 811-815. https:// doi.org/10.1080/08927020500272589

Yang, J.L., Zhang, Z., Schlarb, A.K. and Friedrich, K. (2006). On the characterization of tensile creep resistance of polyamide 66 nanocomposites. Part II: Modeling and prediction of long-term performance. Polymer, 47(19), 6745-6758. https:// doi.org/10.1016/j.polymer.2006.07.060 